\title{
From simple quinoxalines to potent oxazolo[5,4-f]quinoxaline inhibitors of glycogen-synthase kinase 3 (GSK3) ${ }^{\dagger}$
}

Frédéric Lassagne, ${ }^{* a}$ Camille Duguépéroux, ${ }^{a}$ Carlos Roca, ${ }^{b}$ Concepcion Perez, ${ }^{c}$ Ana Martinez, ${ }^{b, d}$ Blandine Baratte, ${ }^{e, f}$ Thomas Robert, $^{\mathrm{e}, \mathrm{f}}$ Sandrine Ruchaud, ${ }^{\mathrm{e}, \mathrm{f}}$ Stéphane Bach, ${ }^{* e, f}$ William Erb, ${ }^{\mathrm{a}}$ Thierry Roisnel ${ }^{\mathrm{a}}$ and Florence Mongin*a

2,7-Disubstituted oxazolo[5,4-f]quinoxalines were synthesized from 6-amino-2-chloroquinoxaline in four steps (iodination at C5, substitution of the chloro group, amidation and copper-catalysed cyclization) and 28 to $44 \%$ overall yields. A 2,8-disubstituted oxazolo[5,4-f]quinoxaline was similarly obtained from 6-amino-3-chloroquinoxaline (39\% overall yield). For the synthesis of other oxazolo[5,4-f]quinoxalines, the amidation was rather performed before the substitution; moreover, time-consuming purifications were avoided between the amines and the final products ( 38 to $54 \%$ overall yields). Finally, a

more efficient way consisting in merging the two last steps in a sequential process was devised to access more derivatives ( 37 to $65 \%$ overall yields). Most of the oxazolo[5,4-f]quinoxalines were evaluated on a panel of protein kinases, and a few 2,8-disubstituted derivatives proved to inhibit the GSK3 kinase. While experiments showed an ATP-competitive inhibition on GSK3 $\beta$, structure-activity relationships allowed to identify 2-(3-pyridyl)-8(thiomorpholino)oxazolo[5,4-f]quinoxaline as the most potent inhibitor with an IC 50 value of about $5 \mathrm{nM}$ on GSK3 .

\section{Introduction}

Oxazolo[5,4-f]quinoxalines have, to our knowledge, never been synthesized before. Their structures can be seen either as a pyrazine fused to a benzoxazole or as an oxazole fused to a quinoxaline ${ }^{1}$ (Fig. 1, top left). Oxazolo[4,5-h]quinolines, which are analogues lacking one nitrogen (Fig. 1, top right), have shown anti-allergic activities. ${ }^{2}$ Thus, it is of interest to access oxazolo[5,4-f]quinoxalines and study their biological behaviour in search of original properties.

It has been shown in 2011 that 2-quinolinol could be functionalized either at its 6- or at its 7-position by nitration at room temperature using potassium nitrate in sulfuric acid or nitric acid in acetic acid, respectively. ${ }^{3}$ Subsequent conversion to the corresponding chlorides (reflux with phosphorus oxychloride and phosphorous pentachloride) and nitro reduction $^{3}$ can easily furnish appropriate substrates (Fig. 1, bottom) to attempt the synthesis of various $2,7-$ and 2,8 -

a. Univ Rennes, CNRS, ISCR (Institut des Sciences Chimiques de Rennes) - UMR 6226, F-35000 Rennes, France. E-mail: florence.mongin@univ-rennes1.fr

b. Centro de Investigaciones Biologicas-CSIC, Ramiro de Maeztu 9, 28040 Madrid, Spain.E-mail: ana.martinez@csic.es

c. Instituto de Química Médica-CSIC, Juan de la Cierva 3, 28006 Madrid, Spain

d. Centro de Investigación Biomédica en Red de Enfermedades Neurodegenerativas (CIBERNED), Instituto Carlos III, 28031 Madrid, Spain

e. Sorbonne Université, CNRS, FR2424, Plateforme de criblage KISSf (Kinase Inhibitor Specialized Screening facility), Station Biologique de Roscoff, Place Georges Teissier, 29682 Roscoff, France. E-mail: bach@sb-roscoff.fr

f. Sorbonne Université, CNRS, UMR 8227, Integrative Biology of Marine Models,

Station Biologique de Roscoff, CS 90074, 29688 Roscoff Cedex, France disubstituted oxazolo[5,4-f]quinoxalines.

We recently became interested in protein kinases as the random screening of original polyaromatic compounds revealed inhibitors. ${ }^{4}$ Following these studies, we report in the present paper an access to these original oxazolo[5,4$f$ ]quinoxalines and the results of their evaluation on a panel of protein kinases. Docking studies are presented, leading to a potent inhibitor of GSK3.
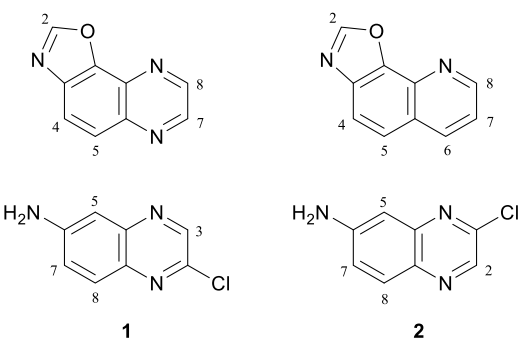

Fig. 1 Top: Structures of oxazolo[5,4-f]quinoxaline (left) and oxazolo[4,5h]quinoline (right). Bottom: Planned quinoxaline substrates.

\section{Results and discussion}

6-Amino-2-chloroquinoxaline (1) was converted into 2,7disubstituted oxazolo[5,4-f]quinoxalines in four steps (Scheme 1). A way to access benzoxazole is to build the ring from a 2haloanilide. ${ }^{5}$ Therefore, inspired by the reported bromination of 6-aminoquinoxaline at $C 5,6$ we treated a solution of 1 in $4: 1$ dioxane-water by an excess of iodine and sodium bicarbonate at room temperature for $4 \mathrm{~h}$. Under these conditions, the 5 - 
iodo derivative 3 , similarly formed regioselectively, was isolated in $88 \%$ yield.

In order to progress towards compounds of biological interest, the chloro group was successfully replaced by morpholino and 4-methylpiperazino at the reflux temperature of toluene, affording $\mathbf{4 a , b}$. Their reaction with benzoyl chloride in the presence of calcium carbonate under similar conditions led to the benzamides $\mathbf{5} \mathbf{a a}$ and $\mathbf{5} \mathbf{a b}$.

Next, we sought simple and efficient conditions with which we could attempt benzoxazole formation. ${ }^{5,7}$ Convinced of the interest of copper-catalysed reactions, we decided to use catalytic copper(I) iodide in the presence of potassium carbonate, and selected dimethylsulfoxide as solvent in order to avoid an additional ligand. As expected, after $12 \mathrm{~h}$ at $110{ }^{\circ} \mathrm{C}$, the 2,7-disubstituted oxazolo[5,4-f]quinoxalines 6aa and 6ab were isolated in good yields.

A similar four-step synthesis, employing isonicotinoyl chloride instead of benzoyl chloride, was used to access the 2,8-disubstituted oxazolo[5,4-f]quinoxaline 10a (Scheme 2).

For the purpose of moving towards a more convergent strategy, we reversed the step order and performed the amidation before the substitution of the chloro group (Scheme 3). A further value of this approach would be the possibility to carry out the substitution under smoother conditions; indeed, the reaction should be favoured with, at $\mathrm{C} 6$, an aroylamino less electron-donating than the previous amino. In a preliminary attempt, the iodide $\mathbf{3}$ was treated with nicotinoyl chloride; to solve some solubility issue sometimes encountered with toluene, acetonitrile containing 5 equivalents of pyridine was rather employed. Next, the chlorocarboxamide 11b was reacted with morpholine in dimethylsulfoxide, a solvent also suitable for the benzoxazole formation, and an excess of potassium carbonate was introduced right from the beginning of the reaction. After the required time to achieve the nucleophilic substitution at room temperature, catalytic copper(I) iodide was introduced and the mixture containing 5ba was warmed to $110{ }^{\circ} \mathrm{C}$ in order to allow the cyclization to take place. Under these conditions, the 2,7-disubstituted oxazolo[5,4-f]quinoxaline 6 ba was isolated after purification in an overall $51 \%$ yield for this three-step sequence (Scheme 3, top).

In a similar way, the iodide $\mathbf{7}$ was readily converted into the carboxamides $\mathbf{1 2 a}, \mathbf{b}$ by using either benzoyl chloride or nicotinoyl chloride. Further replacement of the chloro by morpholino or 4-methylpiperazino benefited from the higher reactivity of $\mathbf{1 2 a , b}$ towards nucleophiles when compared with 11b. From the compounds 9aa, 9ab, 9ba and 9bb, here only isolated from their reaction mixture by a simple work-up to ascertain their formation, cyclization was performed, leading to the new 2,8-disubstituted oxazolo[5,4-f]quinoxalines 10aa, 10ab, 10ba (unambiguously identified by X-ray diffraction; the corresponding ORTEP diagram is given in Fig. 2) and $10 \mathrm{bb}$ (Scheme 3, bottom). It is worth noting that there is no need to purify the intermediates of this three-step synthesis from $\mathbf{7}$ as, after suitable work-up, they can be directly involved in the substitution reaction and benzoxazole formation.
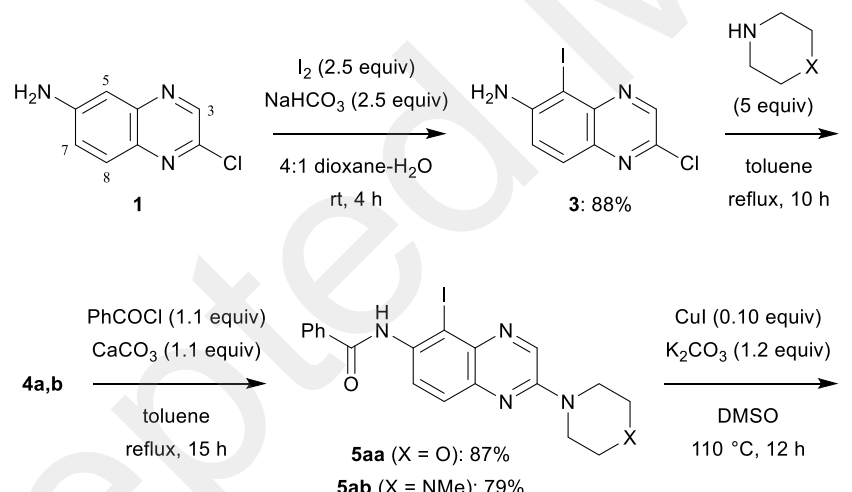

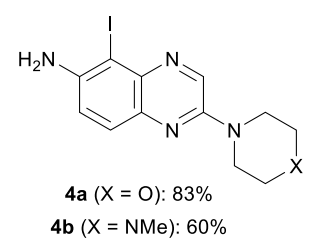

$\mathrm{Ph}$

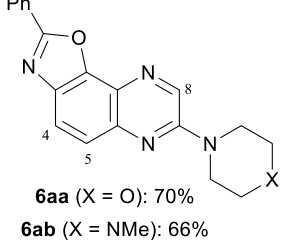

Scheme 1 Synthesis of the 2,7-disubstituted oxazolo[5,4-f]quinoxalines $6 \mathbf{a a}$ and $\mathbf{6 a b}$.

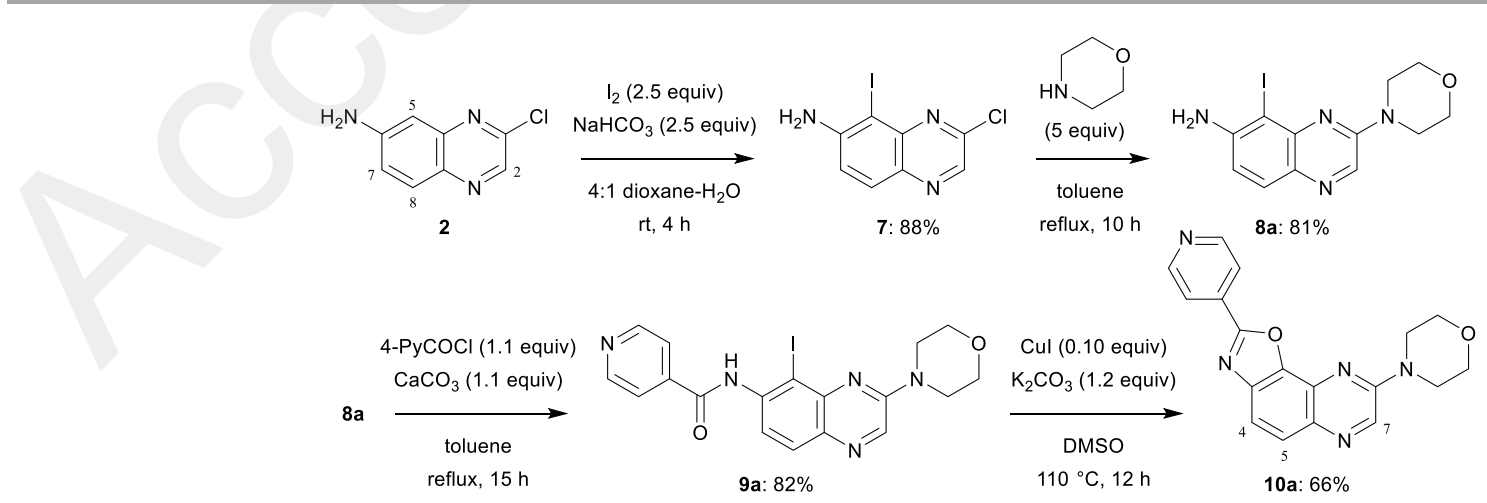



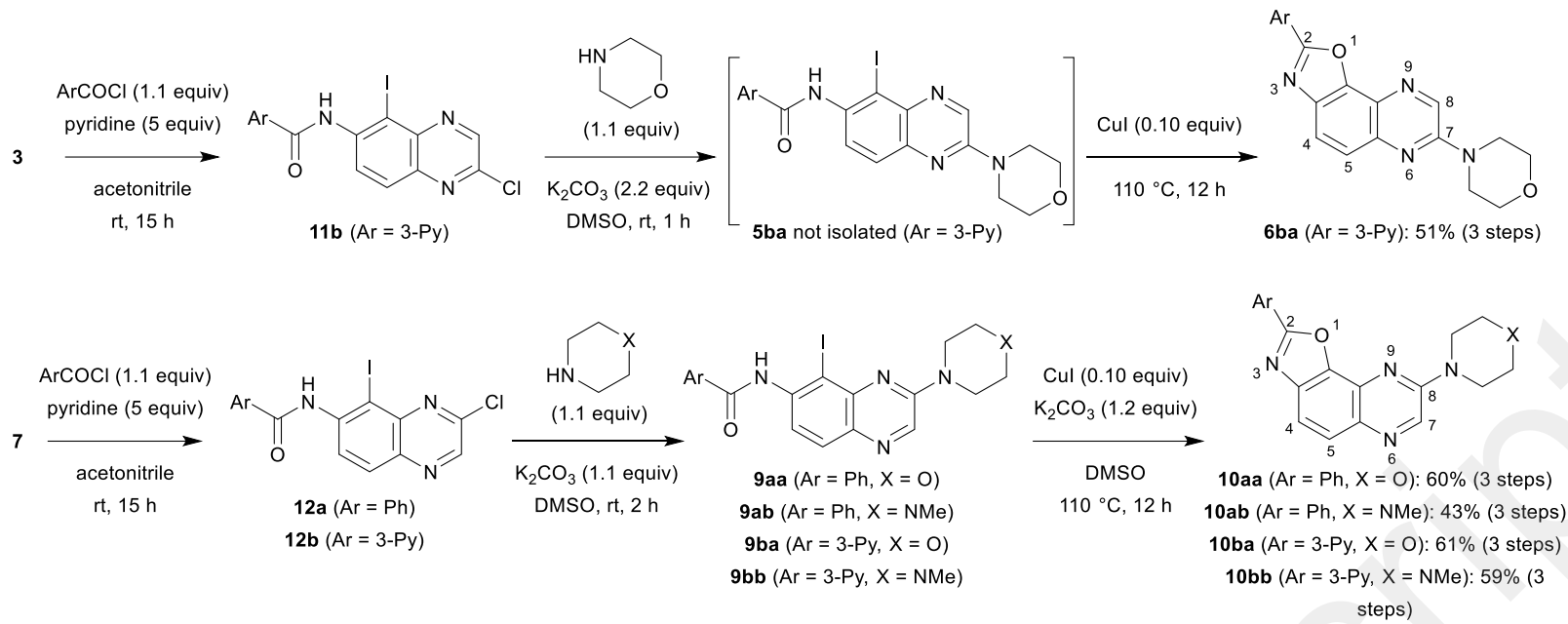

Scheme 3 Synthesis of the 2,7-disubstituted oxazolo[5,4-f]quinoxalines 6 ba and of the 2,8-disubstituted oxazolo[5,4-f]quinoxalines 10aa, 10ab, 10ba and 10bb.

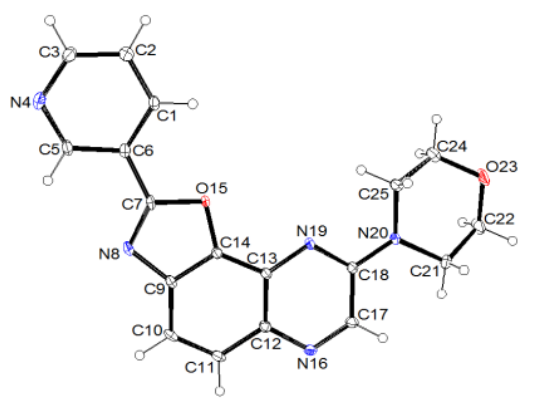

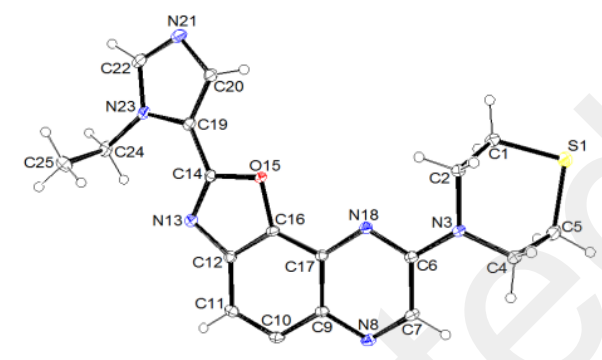

Protein kinases can be deregulated in diseases such as cancers and neurodegenerative disorders. ${ }^{8}$ Since the end of the nineties, this class of signalling biomolecules has become indispensable drug targets. As a result, many candidates are at present undergoing clinical evaluation and 50 FDA-approved kinase inhibitors are already on the market. ${ }^{9}$

In keeping with our ongoing research on novel protein kinase inhibitors, ${ }^{4}$ most of the synthesized oxazolo[5,4$f$ fquinoxalines as well as a few precursors were tested against a short panel of disease-related protein kinases: cyclindependent kinases 2 (CDK2/CyclinA), 5 (CDK5/p25) and 9 (CDK9/CyclinT), proto-oncogene kinase PIM1, CDC2-like kinase 1 (CLK1), dual specificity tyrosine phosphorylation regulated kinase 1A (DYRK1A), glycogen synthase kinase 3 (GSK3; isoform $\beta$, and possibly $\alpha$ or/and $\alpha / \beta$ ), casein kinase 1 (CK1; isoform $\varepsilon$, and possibly $\delta / \varepsilon$ ) and mitotic kinase Haspin (Table 1).

Fig. 2 ORTEP diagrams (30\% probability) of $10 \mathrm{ba}$ (top) and 10ci (bottom).

Table 1 Inhibitory activities of the first round of compounds against a short panel of disease-related protein kinases. The table displays the remaining kinase activities detected after treatment with $10 \mu \mathrm{M}$ of the tested compounds. The values obtained after treatment with $1 \mu \mathrm{M}$ are given in brackets. Results are expressed in \% of maximal activity, i.e. measured in the absence of inhibitor but with an equivalent dose of DMSO (solvent of the tested compounds). ATP concentration used in the kinase assays was $10 \mu$ mol/L (values are means, $\mathrm{n}=2$ ). Kinases are from human origin unless specified: Mm, Mus musculus; Rn, Rattus norvegicus; Ssc, Sus scrofa domesticus.

\begin{tabular}{|c|c|c|c|c|c|c|c|c|c|c|c|c|}
\hline Compd. & CDK2/CyclinA & CDK5/p25 & CDK9/CyclinT & PIM1 & MmCLK1 & RnDYRK1A & GSK3 $\alpha$ & GSK3 $\beta$ & $\operatorname{SscGSK} 3 \alpha / \beta$ & CK1ع & SscCK1 $1 \delta / \varepsilon$ & Haspin \\
\hline 5 aa & - & $\geq 100(99)$ & $90(80)$ & $100(91)$ & $91(95)$ & $100(97)$ & - & $89(92)$ & - & $92(90)$ & - & 77 (87) \\
\hline $5 a b$ & - & $\geq 100(100)$ & $84(79)$ & $\geq 100(\geq 100)$ & $59(90)$ & $89(96)$ & - & $76(92)$ & - & $73(82)$ & - & $68(72)$ \\
\hline $6 a a$ & - & $100(\geq 100)$ & $93(81)$ & $\geq 100(\geq 100)$ & $59(99)$ & $84(93)$ & - & $96(86)$ & - & $83(92)$ & - & $57(60)$ \\
\hline $6 a b$ & - & $\geq 100$ (98) & $72(79)$ & $\geq 100(\geq 100)$ & $44(95)$ & 73 (99) & - & $89(82)$ & - & $86(78)$ & - & $64(82)$ \\
\hline $6 \mathrm{ba}$ & - & $\geq 100(\geq 100)$ & $\geq 100(\geq 100)$ & $99(\geq 100)$ & - & $70(92)$ & $\geq 100(\geq 100)$ & $90(\geq 100)$ & - & $81(\geq 100)$ & - & $87(\geq 100)$ \\
\hline $9 a$ & - & $\geq 100(\geq 100)$ & $69(73)$ & $\geq 100(\geq 100)$ & - & $50(72)$ & $41(72)$ & $54(64)$ & - & $76(88)$ & - & $79(\geq 100)$ \\
\hline $10 a$ & - & $\geq 100$ (99) & $52(79)$ & $78(90)$ & - & $42(74)$ & $24(55)$ & $51(60)$ & - & $72(\geq 100)$ & - & $59(64)$ \\
\hline $9 a a$ & $48(87)$ & $96(91)$ & $25(80)$ & $84(96)$ & - & - & $33(82)$ & $37(82)$ & $43(92)$ & $78(98)$ & - & - \\
\hline 10aa & $70(99)$ & $\geq 100(98)$ & $40(65)$ & $97(94)$ & - & - & $13(52)$ & $33(59)$ & $29(56)$ & $85(\geq 100)$ & - & - \\
\hline $10 a b$ & $52(98)$ & $85(81)$ & $4(61)$ & $75(89)$ & - & - & $\leq 0(54)$ & $12(58)$ & $14(69)$ & $40(94)$ & - & - \\
\hline $10 \mathrm{ba}$ & - & $66(98)$ & $27(45)$ & $23(43)$ & - & $3(11)$ & $9(9)$ & $2(2)$ & - & $65(75)$ & - & $12(23)$ \\
\hline $10 \mathrm{bb}$ & $\geq 100(\geq 100)$ & $93(\geq 100)$ & $7(35)$ & $20(57)$ & - & - & $2(4)$ & $6(6)$ & $16(16)$ & $53(\geq 100)$ & $72(88)$ & $24(29)$ \\
\hline
\end{tabular}


Interestingly, some of the oxazolo[5,4-f]quinoxalines and, to a lesser extent, their non-cyclized precursors proved to significantly inhibit CDK9/CyclinT, DYRK1A and GSK3 at $10 \mu \mathrm{M}$. In addition, at the lower $1 \mu \mathrm{M}$ concentration, a still good activity on GSK3 protein kinase was noticed for the compounds $10 \mathrm{ba}$ and $10 \mathrm{bb}$ bearing a 3-pyridyl ring at $\mathrm{C} 2$. $\mathrm{IC}_{50}$ values were calculated for the most promising compounds; while micromolar values for GSK3 inhibition were found in the case of $10 \mathrm{aa}$ and $10 \mathrm{ab}$, encouraging submicromolar values were recorded for $\mathbf{1 0 b a}$ and $\mathbf{1 0 b b}$ (Table 2).

Table 2 Selected IC $\mathrm{C}_{50}$ values ( $\mathrm{nM}$ ) for compounds of Table 1

\begin{tabular}{llllll}
\hline Entry & Product & CDK9/Cyclint & GSK3 $\alpha$ & GSK3 $\beta$ & SscGSK3 $\alpha / \beta$ \\
\hline 1 & $9 a a$ & 2500 & 2200 & 6800 & 8800 \\
\hdashline 2 & $10 a a$ & $>10000$ & 610 & 980 & 1100 \\
\hline 3 & $10 a b$ & 3100 & 1600 & 3100 & 1900 \\
\hline 4 & $10 \mathrm{ba}$ & - & 15 & 25 & - \\
\hline 5 & 10bb & - & 24 & 55 & 30 \\
\hline
\end{tabular}

Because of its association with key biological processes (metabolism, cell signalling, cellular transport, apoptosis, proliferation, intracellular communication...), the serinethreonine protein kinase GSK3 is implicated in various diseases (type 2 diabetes, bipolar disorder, schizophrenia, Alzheimer's disease, Parkinson's disease, developmental disorders and cancer), and has become an important target for drug development. ${ }^{10}$ Thus, our preliminary results prompted us to identify both the binding site and the binding mode of our best inhibitors 10ba,bb through (i) ATP-competition experiments and (ii) docking studies in order to optimize their structure.

(i) The kinetic mechanism of GSK3 $\beta$ inhibition was experimentally investigated for one of the most potent synthetized derivatives, the quinoxaline $10 \mathrm{bb}$, by varying the concentrations of both ATP and the tested inhibitor in the kinase reaction. The Lineweaver-Burk or double-reciprocal plots of $1 / v$ versus $1 /[$ ATP] at fixed concentrations of the new inhibitor $10 \mathrm{bb}$ showed an intersecting pattern consistent with competitive inhibition as all lines converge at or near the $y$ axis (Fig. 3). These results clearly show this new family of quinoxaline derivatives and specifically compound $10 \mathrm{bb}$ are ATP-competitive GSK3 $\beta$ inhibitors because an increase in the ATP concentration (from 1 to $100 \mu \mathrm{M}$ ) does not interfere with the enzymatic inhibition.

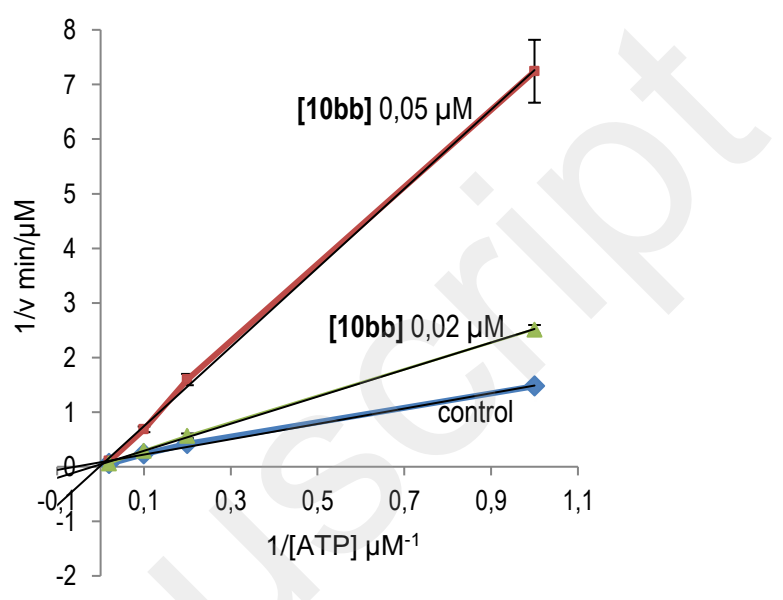

Fig. 3 Kinetic data determined for derivative 10bb. ATP concentrations in the reaction mixture varied from 1 to $100 \mu \mathrm{M}$. Compound concentrations used are depicted in the plot, and the concentration of the substrate was kept constant at 12.5 $\mu \mathrm{M}$. Each point is the mean of two different experiments, each one analysed in duplicate.

(ii) In order to develop structure-activity relationships and propose novel substituents able to increase kinase inhibition potency, we performed docking studies in the ATP-binding cavity of GSK3 $\beta$ for the compounds $10 \mathrm{ab}$ and $10 \mathrm{bb}$. Both compounds are able to bind into the cavity through an $\mathrm{H}$-bond interaction between the $\mathrm{N} 6$ atom of the oxazoloquinoxaline ring (see Scheme 3 for numbering) and the backbone amine group of the Val135 (Fig. 4), orienting the substituent at C2 to the catalytic residue Lys 85 and the substituent at $C 8$ to the solvent. The main difference between both compounds is the substituent at $\mathrm{C} 2$, a phenyl ring (compound 10ab) and a pyridine ring (compound 10bb). The pyridine ring is able to interact through an $\mathrm{H}$-bond interaction with Lys85, increasing the affinity and improving the inhibition of the target. Thus, in order to access more potent inhibitors, we could maintain the pyridine ring or replace it by a five-membered heterocycle that allows similar interaction. The substituent at $\mathrm{C} 8$ is in both cases a piperazine ring that is oriented to the solvent-exposed region. This orientation allows different substituents to be introduced in order to grow up the ligand into this region. Moreover, substituents in this position with aromatic rings could be interesting to allow the interaction with Arg141 through a $\pi$-cation interaction. Furthermore, $\mathrm{H}$-bond acceptor groups in this position could also be able to interact with Arg141. 

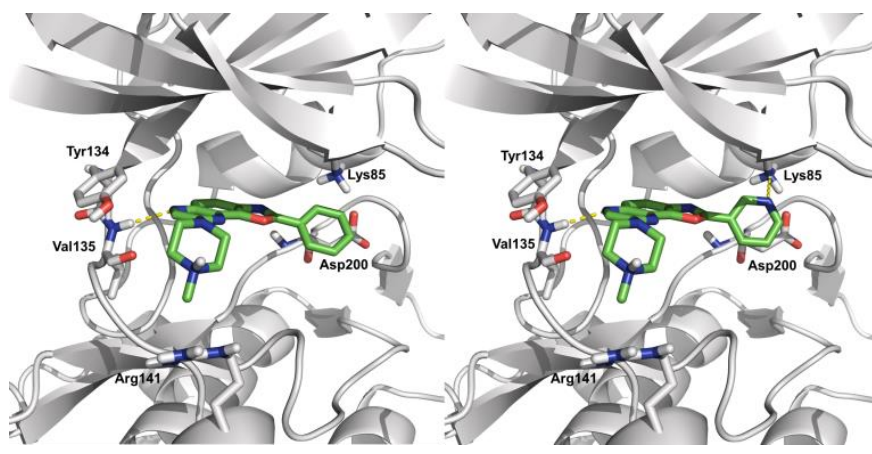

Fig. 4 Proposed binding mode for compounds 10ab (left) and 10bb (right) in the ATP binding pocket of GSK3 $\beta$.

We first decided to keep the pyridine ring at $\mathrm{C} 2$ and replace the morpholine or 4-methylpiperazine present at $\mathrm{C} 8$ by various cyclic amines (Table 3, top scheme). To access the planned structures, we applied the procedure consisting in merging substitution and cyclization to benzoxazole in a sequential process (Scheme 3, top). Indeed, we observed in the course of the synthesis of $6 \mathbf{b a}$ that there was no need to isolate the sequence intermediate $\mathbf{5} \mathbf{b a}$ and to purify the precursor $\mathbf{1 1 b}$. Thus, under these conditions, the 2,8-disubstituted oxazolo[5,4-f]quinoxalines $\mathbf{1 0 b c - b i}$ were prepared from the dihalogenated carboxamide $\mathbf{1 2} \mathbf{b}$ and isolated after purification in yields ranging from 44 to $86 \%$ (Table 3 , entries 1-7).

Then, we prepared 10ci, an analogue of $\mathbf{1 0 b i}$ in which the 3-pyridyl group at C2 is replaced by 1-ethyl-5-imidazolyl (Table 3 , bottom scheme). The idea was to verify if the interaction between Lys 85 and the nitrogen of the ring at $\mathrm{C} 2$ could be improved. The compound 10ci was similarly prepared (Table 3, entry 8 ), and its structure identified unambiguously by X-ray diffraction (see ORTEP diagram in Fig. 2).

These new compounds were evaluated on kinases as previously and compared with 10ba,bb (Table 4). In addition, the dose-dependent effect was tested on GSK3 $\beta$ and GSK3 $\alpha$ for the most promising compounds; the corresponding $\mathrm{IC}_{50}$ values are given in Table 5. Most of the derivatives lost their activities against GSK3, except the compounds $10 \mathrm{bg}$ and $10 \mathrm{bi}$ which behaved as 10 ba against GSK3 $\beta$, but gained potency towards GSK3 $\alpha$. It is worth noting that, in spite of similar ring sizes, increasing activities are noticed from $10 \mathrm{ba}$ to $10 \mathrm{bg}$ and 10bi, suggesting that either conformational changes or additional interactions might occur with these last compounds. Finally, the dose-dependent effect on DYRK1A was determined for 10ba, 10bg, 10bi and 10ci, and showed a rather good preference of these inhibitors for GSK3 when compared with DYRK1A.

Table 3 Synthesis of the 2,8-disubstituted oxazolo[5,4-f]quinoxalines 10bc-bi and 10ci.

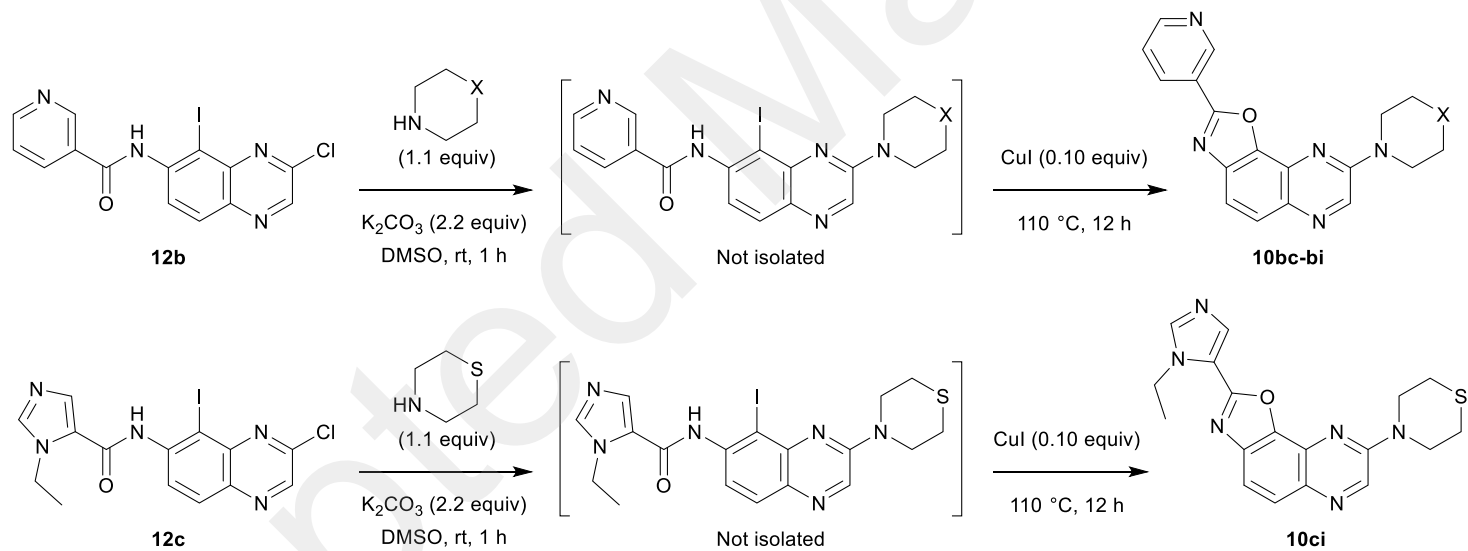

\begin{tabular}{|c|c|c|c|}
\hline Entry & Product & $x$ & Yield (\%) \\
\hline 1 & $10 \mathrm{bc}$ & $\widehat{N}_{\mathrm{Ph}}$ & 76 \\
\hline 2 & $10 \mathrm{bd}$ & & 86 \\
\hline 3 & 10be & & 76 \\
\hline $4^{a}$ & $10 \mathrm{bf}$ & $N^{-H}$ & 44 \\
\hline 5 & $10 \mathrm{bg}$ & $\mathrm{CH}_{2}$ & 78 \\
\hline 6 & $10 \mathrm{bh}$ & & 49 \\
\hline 7 & $10 \mathrm{bi}$ & $S$ & 83 \\
\hline 8 & $10 \mathrm{ci}$ & - & 67 \\
\hline
\end{tabular}


Table 4 Inhibitory activities of the optimized compounds against a short panel of disease-related protein kinases. The table displays the remaining kinase activities detected after treatment with $10 \mu \mathrm{M}$ of the tested compounds. The values obtained after treatment with $1 \mu \mathrm{M}$ are given in brackets. Results are expressed in \% of maximal activity, i.e. measured in the absence of inhibitor but with an equivalent dose of DMSO (solvent of the tested compounds). ATP concentration used in the kinase assays was $10 \mu \mathrm{mol} / \mathrm{L}$ (values are means, $\mathrm{n}=2$ ). Kinases are from human origin unless specified: Mm, Mus musculus; Rn, Rattus norvegicus; Ssc, Sus scrofa domesticus.

\begin{tabular}{|c|c|c|c|c|c|c|c|c|c|c|c|}
\hline Compd. & CDK2/CyclinA & CDK5/p25 & CDK9/CyclinT & PIM1 & RnDYRK1A & GSK3 $\alpha$ & GSK3 $\beta$ & $\operatorname{SscGSK} 3 \alpha / \beta$ & CK1ع & $\operatorname{SscCK} 1 \delta / \varepsilon$ & Haspin \\
\hline $10 \mathrm{ba}$ & - & $66(98)$ & $27(45)$ & $23(43)$ & $3(11)$ & $9(9)$ & $2(2)$ & - & $65(75)$ & - & $12(23)$ \\
\hline $10 \mathrm{bb}$ & $\geq 100(\geq 100)$ & $93(\geq 100)$ & $7(35)$ & $20(57)$ & - & $2(4)$ & $6(6)$ & $16(16)$ & $53(\geq 100)$ & $72(88)$ & $24(29)$ \\
\hline $10 b c$ & - & 77 (97) & $31(82)$ & $86(79)$ & $3(41)$ & $11(19)$ & $\leq 0(15)$ & - & $69(\geq 100)$ & - & $30(77)$ \\
\hline 10bd & - & $67(69)$ & $29(69)$ & $29(80)$ & $14(25)$ & $\leq 0(\leq 0)$ & $10(16)$ & - & $51(84)$ & - & $26(64)$ \\
\hline 10be & - & $76(\geq 100)$ & 30 (69) & $\geq 100(\geq 100)$ & $8(51)$ & $9(9)$ & $3(13)$ & - & $74(96)$ & - & $43(54)$ \\
\hline $10 \mathrm{bf}$ & - & $63(84)$ & $1(4)$ & $46(\geq 100)$ & $16(28)$ & $4(11)$ & $2(9)$ & - & $11(46)$ & - & $7(16)$ \\
\hline $10 \mathrm{bg}$ & - & $58(97)$ & $11(40)$ & $13(\geq 100)$ & $4(21)$ & $11(13)$ & $1(5)$ & - & $83(93)$ & - & $21(58)$ \\
\hline 10bh & - & $98(87)$ & $10(49)$ & $87(\geq 100)$ & $2(30)$ & $1(8)$ & $5(20)$ & - & $56(85)$ & - & $10(44)$ \\
\hline $10 \mathrm{bi}$ & - & $53(99)$ & $4(69)$ & $18(\geq 100)$ & $5(19)$ & $\leq 0(\leq 0)$ & $21(14)$ & - & $44(86)$ & - & $8(63)$ \\
\hline 10ci & - & 47 (95) & $9(26)$ & $12(40)$ & $4(24)$ & $2(5)$ & $8(9)$ & - & $78(\geq 100)$ & - & $16(48)$ \\
\hline
\end{tabular}

Table $5 \quad \mathrm{IC}_{50}$ values (nM) for the most promising inhibitors of GSK3. ${ }^{a}$

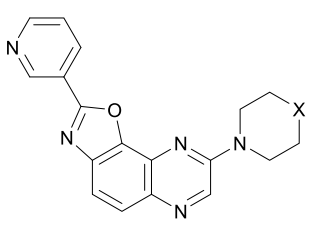

10ba-bi

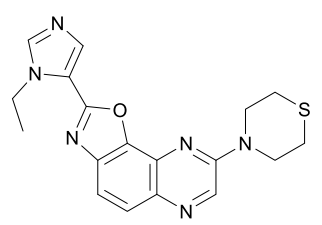

$10 \mathrm{ci}$

\begin{tabular}{|c|c|c|c|c|c|c|}
\hline Entry & Product & $x$ & GSK3 $\alpha$ & GSK3 $\beta$ & $b$ & $R n$ DYRK1A \\
\hline 1 & $10 \mathrm{ba}$ & 0 & 15 & 25 & 1.7 & 200 \\
\hline 2 & $10 \mathrm{bb}$ & $\mathrm{N}-\mathrm{Me}$ & 24 & 55 & 2.3 & - \\
\hline 3 & $10 \mathrm{bc}$ & $\mathrm{N}$-benzyl & 40 & 102 & 2.55 & - \\
\hline 4 & $10 \mathrm{bd}$ & $\begin{array}{l}\mathrm{N}-\mathrm{CH}_{2}-5-(1,3- \\
\text { benzodioxolyl) }\end{array}$ & 88 & 127 & 1.4 & - \\
\hline 5 & 10be & $\mathrm{N}-\mathrm{Boc}$ & 57 & 97 & 1.7 & - \\
\hline 6 & $10 \mathrm{bf}$ & $\mathrm{N}-\mathrm{H}$ & 24 & 68 & 2.8 & - \\
\hline 7 & $10 \mathrm{bg}$ & $\mathrm{CH}_{2}$ & 11 & 33 & 3.0 & 390 \\
\hline 8 & 10bh & $\mathrm{CH}$-morpholino & 22 & 35 & 1.6 & - \\
\hline 9 & $10 \mathrm{bi}$ & $S$ & 4.8 & 22 & 4.6 & 130 \\
\hline 10 & $10 \mathrm{ci}$ & - & 31 & 50 & 1.6 & 447 \\
\hline 11 & \multicolumn{2}{|c|}{ Indirubine-3'-monoxime } & 72 & $55(22)^{c, 11}$ & 0.76 & - \\
\hline 12 & \multicolumn{2}{|c|}{ Hymenialdisine } & 3.6 & $10(10)^{c, 12}$ & 2.8 & - \\
\hline 13 & \multicolumn{2}{|c|}{ Alsterpaullone } & $30(4)^{c, 13}$ & $22(4)^{c, 13}$ & 0.73 & - \\
\hline $14^{14}$ & \multicolumn{2}{|c|}{ CHIR 98014} & 7.0 & 0.6 & 0.09 & - \\
\hline $15^{15}$ & \multicolumn{2}{|c|}{ LY2090314 } & 1.5 & 0.9 & 0.60 & - \\
\hline $16^{16}$ & \multicolumn{2}{|c|}{ BRD0705 } & 66 & 515 & 7.8 & - \\
\hline $17^{17}$ & \multicolumn{2}{|l|}{ G28_14 } & 33 & 218 & 6.6 & - \\
\hline
\end{tabular}

$a$ Three known inhibitors (Indirubine-3'-monoxime, Hymenialdisine and Alsterpaullone) were also measured as controls. Values obtained from the literature for known potent or selective inhibitors were also added for comparison.

${ }^{b} \mathrm{IC}_{50}(\mathrm{GSK} 3 \beta) / \mathrm{IC}_{50}(\mathrm{GSK} 3 \alpha)$ as an evaluation of the isoform selectivity.

${ }^{c}$ Value obtained from the literature (radioactive method using $15 \mu \mathrm{M}$ ATP).

\section{Conclusions}

Thus, these results allowed us to identify the oxazolo[5,4$f$ ]quinoxalines 10ba, 10bg and 10bi as strong ATP-competitive inhibitors of GSK3. The most potent GSK3 inhibitors reported in the literature are pyrimidine CHIR $\mathbf{9 8 0 1 4}^{14}$ and bis(aryl)maleimide LY2090314, ${ }^{15}$ which have subnanomolar or nanomolar $\mathrm{IC}_{50}$ values (Fig. 5, left; Table 5, entries 14 and 15); however, while CHIR 98014 inhibits selectively GSK3ß,
LY2090314 binds almost equally to GSK3 $\alpha$ and GSK3 $\beta$. In contrast, while inhibitors with high isoform-selectivity for

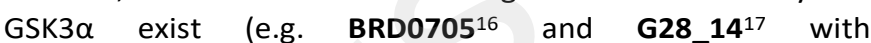
$\mathrm{IC}_{50}(\mathrm{GSK} 3 \beta) / \mathrm{IC}_{50}(\mathrm{GSK} 3 \alpha)$ ratios of 7.8 and 6.6 , respectively), they are less potent (Fig. 5, right; Table 5, entries 16 and 17). Our best inhibitor, the sulphur-containing molecule 10bi, is both potent and more easily binds GSK3 $\alpha$ than GSK3 $\beta$ (ratio of 4.6). Thus, it will be the subject of further studies aimed at identifying potent and selective inhibitors of GSK3 $\alpha$. It is indeed of interest to identify isoform-selective kinase inhibitors for the development of new therapies. ${ }^{17}$ Efforts devoted to cellular tests in order to identify and develop applications for this new family of heterocycles are also ongoing in the lab.

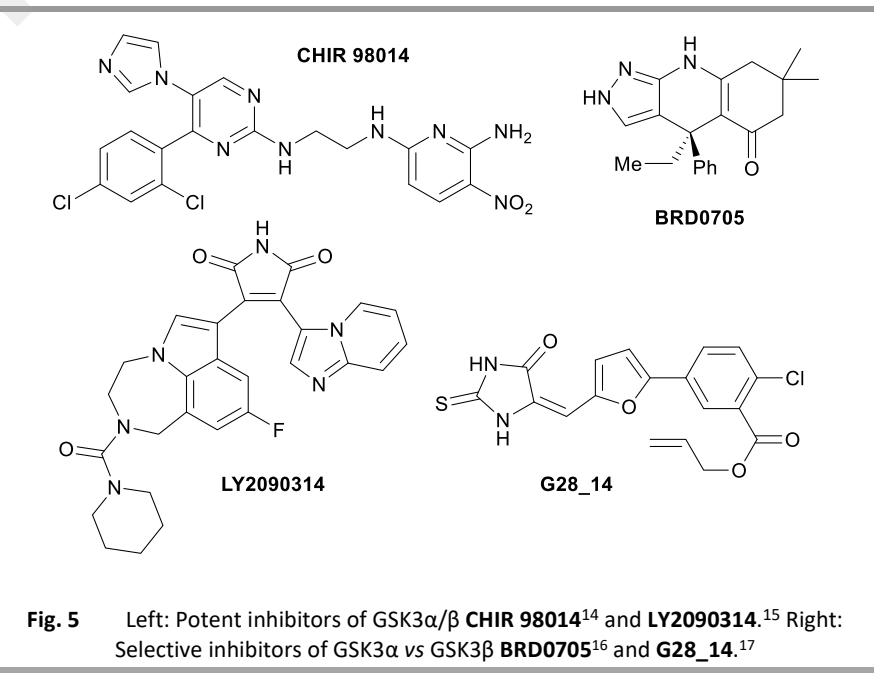

\section{Experimental section}

Procedure used to convert $12 \mathrm{~b}$ into $10 \mathrm{bi}$.

To a suspension of the iodinated amide $12 \mathbf{b}(0.41 \mathrm{~g}, 1.0 \mathrm{mmol})$ in dry DMSO $(4 \mathrm{~mL})$ was added thiomorpholine $(0.11 \mathrm{~mL}, 1.1$ $\mathrm{mmol}$ ) and potassium carbonate $(0.29 \mathrm{~g}, 2.2 \mathrm{mmol})$. After stirring at room temperature for $1 \mathrm{~h}$, copper $(\mathrm{I})$ iodide $(19 \mathrm{mg}$, $0.10 \mathrm{mmol}$ ) was added. The tube was sealed, heated at $110^{\circ} \mathrm{C}$ 
for $12 \mathrm{~h}$ and then cooled. The resulting dark mixture was poured onto cold water $(20 \mathrm{~mL})$; the precipitate was filtered, washed with cold water $(5 \mathrm{~mL})$ and dissolved into chloroform. The organic layer was dried over sodium sulphate and the solvent was removed under reduced pressure. The product was purified by chromatography over silica gel (eluent: $\mathrm{CHCl}_{3-}$ $\mathrm{MeOH}$ 97:3).

\section{Kinetic studies.}

Kinetic experiments were performed by varying the concentrations of ATP (from 1 to $100 \mu \mathrm{M}$ ) and inhibitor 10bb $(0,05$ and $0,02 \mu \mathrm{M})$, while the substrate GS2 concentration was kept constant $(12,5 \mu \mathrm{M})$. The ADP-Glo Kinase Assay ${ }^{18}$ was used. Double-reciprocal plotting of the data is depicted in Fig. 3.

\section{Docking studies.}

Before the docking studies, ligands and target need to be preprocessed. Ligands were prepared for docking using LigPrep tool, ${ }^{19}$ using OPLS2005 force field, and calculating the protonating state at $\mathrm{pH}=7.2 \pm 0.2$. For the target preprocessing, Maestro Protein Preparation Wizard ${ }^{20}$ was used. The crystallographic structure of GSK3 $\beta$ in complex with a known inhibitor (PDBID 4ACD)21 was preprocessed, adding the hydrogen atoms, deleting the counterions and water molecules, and protonating the residues at $\mathrm{pH}=7.2$. To develop the docking studies we used $\mathrm{Glide}^{22}$ to perform the docking calculations using the Extra Precision Glide mode. The grid innerbox size was $16 \times 16 \times 16 \AA$ and the outerbox size was $33.5 \times 33.5 \times 33.5 \AA$. The grid box was centred on coordinates $0.432,9.255,31.434$, that correlate with the centre of the ATPbinding site. 10 poses per ligand were calculated and classified by the binding energy. To validate the docking protocol, we have employed some GSK3 $\beta$ inhibitors with known binding mode into the ATP-binding site of the enzyme. ${ }^{16,22-23}$

\section{Conflicts of interest}

There are no conflicts to declare.

\section{Acknowledgements}

We thank the Universite de Rennes 1 and the Centre National de la Recherche Scientifique for supporting this research. We acknowledge the Fonds Européen de Développement Régional (FEDER; D8 VENTURE Bruker AXS diffractometer). A. M. acknowledges financial support from MICU (grant no. SAF2016-76693-R) and ISCiii (CIBERNED, grant no. CB18/05/00040). S. B. and S. R. also thank the Cancéropôle Grand Ouest (axis: natural sea products in cancer treatment), IBiSA (French Infrastructures en sciences du vivant: biologie, santé et agronomie) and Biogenouest (Western France life science and environment core facility network) for supporting KISS $f$ screening facility. We also thank Aurélie Assicot for her contribution to the study and Ludovic Paquin for generous gift of secondary amines.

\section{Notes and references}

1 T. Eicher, S. Hauptmann and A. Speicher, The Chemistry of Heterocycles: Structure, Reactions Synthesis and Applications, 2nd Edition, Wiley-VCH, Weinheim, 2003.

2 J. H. Musser, H. Jones, S. Sciortino, K. Bailey, S. M. Coutts, A. Khandwala, P. Sonnino-Goldman, M. Leibowitz, P. Wolf and E. S. Neiss, J. Med. Chem., 1985, 28, 1255.

3 J. Deng, E. Feng, S. Ma, Y. Zhang, X. Liu, H. Li, H. Huang, J. Zhu, W. Zhu, X. Shen, L. Miao, H. Liu, H. Jiang and J. Li, J. Med. Chem., 2011, 54, 4508.

4 N. Mokhtari Brikci-Nigassa, G. Bentabed-Ababsa, W. Erb, F. Chevallier, L. Picot, L. Vitek, A. Fleury, V. Thiery, M. Souab, T. Robert, S. Ruchaud, S. Bach, T. Roisnel and F. Mongin, Tetrahedron, 2018, 74, 1785; N. Mokhtari Brikci-Nigassa, L. Nauton, P. Moreau, O. Mongin, R. E. Duval, L. Picot, V. Thiéry, M. Souab, S. Ruchaud, S. Bach, R. Le Guevel, G. Bentabed-Ababsa, W. Erb, T. Roisnel, V. Dorcet and F. Mongin, Bioorg. Chem., 2019, 82, DOI: 10.1016/j.bioorg.2019.103347.

5 G. Evindar and R. A. Batey, J. Org. Chem., 2006, 71, 1802.

6 X. Hui, J. Desrivot, C. Bories, P. M. Loiseau, X. Franck, R. Hocquemiller and B. Figadère, Bioorg. Med. Chem. Lett., 2006, 16, 815.

7 (a) W. R. Bowman, H. Heaney and P. H. G. Smith, Tetrahedron Lett., 1982, 23, 5093; (b) T. Minami, T. Isonaka, Y. Okada and J. Ichikawa, J. Org. Chem., 1993, 58, 7009; (c) B. A. Lanman, V. J. Cee, S. R. Cheruku, M. Frohn, J. Golden, J. Lin, M. Lobera, Y. Marantz, K. M. Muller, S. C. Neira, A. J. Pickrell, D. Rivenzon-Segal, N. Schutz, A. Sharadendu, X. Yu, Z.-D. Zhang, J. Buys, M. Fiorino, A. Gore, M. Horner, A. Itano, M. McElvain, S. Middleton, M. Schrag, H. M. Vargas, H. Xu, Y. $\mathrm{Xu}, \mathrm{X}$.-X. Zhang, J. Siu and R. W. Burli, ACS Med. Chem. Lett., 2011, 2, 102; (d) J. Peng, C. Zong, M. Ye, T. Chen, D. Gao, Y. Wang and C. Chen, Org. Biomol. Chem., 2011, 9, 1225; (e) J.H. Jia, C.-L. Jiang, X.-J. Zhang, Y.-W. Jiang and D.-W. Ma, Tetrahedron Lett., 2011, 52, 5593; (f) V. Kavala, D. Janreddy, M. J. Raihan, C.-W. Kuo, C. Ramesh and C.-F. Yao, Adv. Synth. Catal., 2012, 354, 2229; (g) P. J. Tambade, Y. P. Patil, Z. S. Qureshi, K. P. Dhake and B. M. Bhanage, Synth. Commun., 2012, 42, 176; (h) A. Ahmed, R. Singha and J. K. Ray, Tetrahedron Lett., 2015, 56, 2167; (i) T. Venu Saranya, P. Rajan Sruthi and S. Anas, Synth. Commun., 2019, 49, 297.

8 S. Klaeger, S. Heinzlmeir, M. Wilhelm, H. Polzer, B. Vick, P.-A. Koenig, M. Reinecke, B. Ruprecht, S. Petzoldt, C. Meng, J. Zecha, K. Reiter, H. Qiao, D. Helm, H. Koch, M. Schoof, G. Canevari, E. Casale, S. R. Depaolini, A. Feuchtinger, Z. Wu, T. Schmidt, L. Rueckert, W. Becker, J. Huenges, A.-K. Garz, B.-O. Gohlke, D. P. Zolg, G. Kayser, T. Vooder, R. Preissner, H. Hahne, N. Tonisson, K. Kramer, K. Goetze, F. Bassermann, J. Schlegl, H.-C. Ehrlich, S. Aiche, A. Walch, P. A. Greif, S. Schneider, E. R. Felder, J. Ruland, G. Medard, I. Jeremias, K. Spiekermann and B. Kuster, Science, 2017, 358, 1148.

9 (a) R. Roskoski, Jr., Pharmacol. Res., 2019, 144, 19; (b) H. L. Lightfoot, F. W. Goldberg and J. Sedelmeier, ACS Med. Chem. Lett., 2019, 10, 153.

10 (a) M. K. Pandey and T. R. DeGrado, Theranostics, 2016, 6, 571; (b) A. P. Saraswati, S. M. Ali Hussaini, N. H. Krishna, B. N. Babu and A. Kamal, Eur. J. Med. Chem., 2018, 144, 843.

11 S. Leclerc, M. Garnier, R. Hoessel, D. Marko, J. A. Bibb, G. L. Snyder, P. Greengard, J. Biernat, Y.-Z. Wu, E.-M. Mandelkow, G. Eisenbrand and L. Meijer, J. Biol. Chem., 2001, 276, 251.

12 L. Meijer, A. M. W. H. Thunnissen, A. W. White, M. Garnier, M. Nikolic, L. H. Tsai, J. Walter, K. E. Cleverley, P. C. Salinas, Y. Z. Wu, J. Biernat, E. M. Mandelkow, S. H. Kim and G. R. Pettit, Chem. Biol., 2000, 7, 51.

13 M. Leost, C. Schultz, A. Link, Y.-Z. Wu, J. Biernat, E.-M. Mandelkow, J. A. Bibb, G. L. Snyder, P. Greengard, D. W. 
Zaharevitz, R. Gussio, A. M. Senderowicz, E. A. Sausville, C. Kunick and L. Meijer, Eur. J. Biochem., 2000, 267, 5983.

14 A. S. Wagman, R. S. Boyce, S. P. Brown, E. Fang, D. Goff, J. M. Jansen, V. P. Le, B. H. Levine, S. C. Ng, Z.-J. Ni, J. M. Nuss, K. B. Pfister, S. Ramurthy, P. A. Renhowe, D. B. Ring, W. Shu, S. Subramanian, X. A. Zhou, C. M. Shafer, S. D. Harrison, K. W. Johnson and D. E. Bussiere, J. Med. Chem., 2017, 60, 8482.

15 J. M. Atkinson, K. B. Rank, Y. Zeng, A. Capen, V. Yadav, J. Manro, T. A. Engler and M. Chedid, PLoS One, 2015, 10, e0125028/1.

16 F. F. Wagner, L. Benajiba, A. J. Campbell, M. Weiewer, J. R. Sacher, J. P. Gale, L. Ross, A. Puissant, G. Alexe, A. Conway, M. Back, Y. Pikman, I. Galinsky, D. J. Deangelo, R. M. Stone, T. Kaya, X. Shi, M. B. Robers, T. Machleidt, J. Wilkinson, O. Hermine, A. Kung, A. J. Stein, D. Lakshminarasimhan, M. T. Hemann, E. Scolnick, Y.-L. Zhang, J. Q. Pan, K. Stegmaier and E. B. Holson, Sci. Transl. Med., 2018, 10, eaam8460/1.

17 Y. Wang, X. Dou, L. Jiang, H. Jin, L. Zhang, L. Zhang and Z. Liu, Eur. J. Med. Chem., 2019, 171, 221.

18 ADP-Glo KM Kinase Assay Technical Manual: https://www.promega.es/resources/protocols/technicalmanuals/0/adp-glo-kinase-assay-protocol/ (July 30, 2019).

19 Schrödinger Release 2016-4: LigPrep, Schrödinger, LLC, New York, NY, 2019.

20 M. G. Sastry, M. Adzhigirey, T. Day, R. Annabhimoju and W. Sherman, J. Comput. Aided Mol. Des., 2013, 27, 221.
21 S. Berg, M. Bergh, S. Hellberg, K. Högdin, Y. Lo-Alfredsson, P. Söderman, S. von Berg, T. Weigelt, M. Ormö, Y. Xue, J. Tucker, J. Neelissen, E. Jerning, Y. Nilsson and R. Bhat, J. Med. Chem., 2012, 55, 9107.

22 R. A. Friesner, R. B. Murphy, M. P. Repasky, L. L. Frye, J. R. Greenwood, T. A. Halgren, P. C. Sanschagrin and D. T. Mainz, J. Med. Chem., 2006, 49, 6177.

(a) S. H. Liang, J. M. Chen, M. D. Normandin, J. S. Chang, G. C. Chang, C. K. Taylor, P. Trapa, M. S. Plummer, K. S. Para, E. L. Conn, L. Lopresti-Morrow, L. F. Lanyon, J. M. Cook, K. E. G. Richter, C. E. Nolan, J. B. Schachter, F. Janat, Y. Che, V. Shanmugasundaram, B. A. Lefker, B. E. Enerson, E. Livni, L. Wang, N. J. Guehl, D. Patnaik, F. F. Wagner, R. Perlis, E. B. Holson, S. J. Haggarty, G. El Fakhri, R. G. Kurumbail and N. Vasdev, Angew. Chem., Int. Ed. Engl., 2016, 55, 9601; (b) F. F. Wagner, L. Benajiba, A. J. Campbell, M. Weiewer, J. R. Sacher, J. P. Gale, L. Ross, A. Puissant, G. Alexe, A. Conway, M. Back, Y. Pikman, I. Galinsky, D. J. Deangelo, R. M. Stone, T. Kaya, X. Shi, M. B. Robers, T. Machleidt, J. Wilkinson, O. Hermine, A. Kung, A. J. Stein, D. Lakshminarasimhan, M. T. Hemann, E. Scolnick, Y.-L. Zhang, J. Q. Pan, K. Stegmaier and E. B. Holson, Sci. Transl. Med., 2018, 10, eaam8460/1; (c) F. X. Tavares, J. A. Boucheron, S. H. Dickerson, R. J. Griffin, F. Preugschat, S. A. Thomson, T. Y. Wang and H.-Q. Zhou, J. Med. Chem., 2004, 47, 4716.

Graphical abstract

\section{From simple quinoxalines to potent oxazolo[5,4-f]quinoxaline inhibitors of glycogen-synthase kinase 3 (GSK3)}

New potent inhibitors of protein kinase GSK3 $\alpha$ were synthesized from 6-amino-3-chloroquinoxaline.

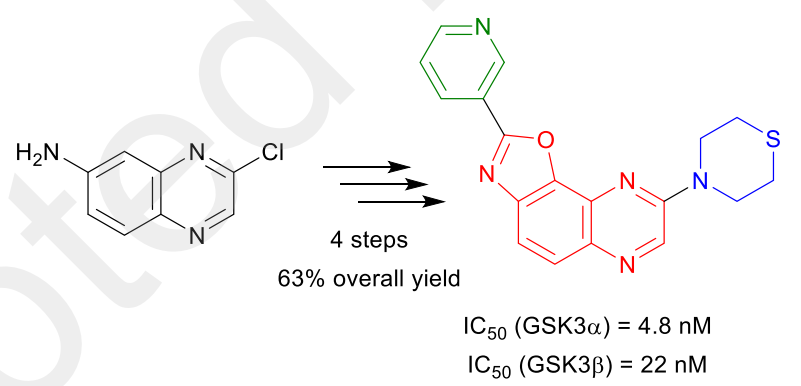

